Журнал«Герстективита інновації наукиљ

(Серія «Гедагогіка», Серія «Гиихологія», Серія «Медицинв»

№(6) 2022

УДК 378.14:51

https://doi.org/10.52058/2786-4952-2022-1(6)-284-293

Насонова Світлана Сергіївна кандидат технічних наук, доцент, доцент кафедри економічної та інформаційної безпеки, Дніпропетровський державний університет внутрішніх справ, проспект Гагаріна, 26, м. Дніпро, 49005, тел.: (097) 940-98-56, https://orcid.org/0000-0002-7228-7499

\title{
СУЧАСНИЙ ПІДХІД ДО ВИКЛАДАННЯ МАТЕМАТИЧНИХ ДИСЦИПЛІН У ВИЩИХ НАВЧАЛЬНИХ ЗАКЛАДАХ
}

Анотація. В даний час все частіше потрібні фахівці, здатні до аналітичного мислення, всебічно розвинені, які можуть приймати ефективні рішення в нестандартних ситуаціях. Основна мета вищої школи - підготовка кваліфікованих кадрів, які глибоко знають свою спеціальність, креативно мислять, здатні до прийняття рішень за допомогою логіки. Вмінню логічно мислити вчить нас математика. Попри всю важливість математики в професійній діяльності людей, іiі вивчення у вищих навчальних закладах має ряд проблем. Однією з них є відсутність у студентів мотивації при вивченні математичних дисциплін. 3 метою підвищення мотивації до навчання необхідно по-перше, робити акцент на практичному застосуванні отриманих теоретичних знань у майбутній професійній діяльності. По-друге, треба залучати до навчального процесу сучасні інформаційні технології (у тому числі мобільні інформаційні технології). Саме поєднання теорії, практики та інформаційних технологій у навчальному процесі дозволить зробити викладання математики більш зрозумілим та цікавим для студентів. Отже, для ефективного вивчення математики у вищих навчальних закладах освіти необхідно коректувати існуючі методики викладання, приймаючи до уваги інтереси та потреби студентської аудиторії.

В статті пропонується переглянути навчальний контент 3 дисципліни «Вища математика», доповнивши його прикладами розв'язання задач, орієнтованих на професійну діяльність здобувачів освіти та їх чисельною реалізацією за допомогою інформаційних технологій. Розглядається методика викладання вищої математики в навчальному закладі. Демонструється викладання однієї 3 тем вищої математики студентам економічних спеціальностей на прикладі роз'язання задачі міжгалузевого балансу. Для чисельної реалізації поставленої задачі використовуються мобільні додатки Matrix Calculator та MS Excel. Для більш повного засвоєння матеріалу студентам пропонується проаналізувати отримані результати та зробити висновки по темі.

Запропонована методика містить елементи інноваційної освіти та орієнтована на розвиток особистісного потенціалу слухачів. Навчаючись за 
цією методикою, студенти набувають навички роботи в команді, вчаться розв'язувати прикладні задачі професійної спрямованості, застосовуючи для цього новітні інформаційні технології.

Ключові слова: математика, інформаційні технології, методика викладання, інноваційна освіта, вищий навчальний заклад.

Nasonova Svitlana Serhiivna Candidate of Technical Sciences, Associate Professor of the Department of Economic and Information Security, Dnipropetrovsk State University of Internal Affairs, Gagarina Ave., 26, Dnipro, 49005, tel.: (097) 940-98-56, https://orcid.org/0000-0002-7228-7499

\section{MODERN APPROACH TO TEACHING MATHEMATICAL DISCIPLINES IN HIGHER EDUCATION INSTITUTIONS}

Abstract. Today more and more specialists are needed, capable of analytical thinking, comprehensively developed, who can make effective decisions in nonstandard situations. The main goal of high school is to train qualified personnel who know their specialty deeply, think creatively, and are able to make decisions with the help of logic. Mathematics teaches us the ability to think logically. Despite the importance of mathematics in the professional activities of people, its study in higher education has a number of problems. One of them is the lack of motivation of students in the study of mathematical disciplines. In order to increase motivation to learn, it is necessary, first of all, to emphasize the practical application of theoretical knowledge in future professional activities. Secondly, it is necessary to involve modern information technologies (including mobile information technologies) in the educational process. The combination of theory, practice and information technology in the educational process will make the teaching of mathematics more understandable and interesting for students. Therefore, in order to effectively study mathematics in higher education, it is necessary to adjust existing teaching methods, taking into account the interests and needs of the student audience.

The article proposes to review the educational content of the discipline "Higher Mathematics", supplementing it with examples of solving applied problems focused on the professional activities of students and their numerical implementation with the help of information technology. The method of teaching higher mathematics in a higher educational institution has been developed; demonstrated how to teach the methods of linear algebra to students of economic specialties on the example of solving the problem of intersectoral balance. Matrix Calculator and MS Excel mobile applications are used to numerically implement this task. For a more complete assimilation of the material, students are invited to analyze the results and draw conclusions on the topic.

The proposed methodology contains elements of innovative education and focuses on the development of personal potential of students. By studying this technique, students acquire skills of teamwork, learn to solve applied problems of 
Журнал«Герстективита інновації наукиљ

(Серія «Гедагогіка», Серія«Гтихологія», Серія«Медицинв»

№1(6) 2022

professional orientation, using the modern information technology.

Keywords: mathematics, information technology, higher education institution, teaching methods, innovative education, higher education institution.

Постановка проблеми. В даний час все частіше потрібні фахівці, здатні до аналітичного мислення, всебічно розвинені, які можуть приймати ефективні рішення в нестандартних ситуаціях.

Основна мета вищої школи - підготовка кваліфікованих кадрів, глибоко знаючих свою спеціальність, креативно мислячих, здатних до прийняття рішень за допомогою логіки $[1,2]$. Вмінню логічно мислити вчить нас математика. «Математику вже тому вчити треба, бо вона розум до ладу приводить» - говорив М.В. Ломоносов. Попри всю важливість математики в професійній діяльності людей, іiі вивчення у вищих навчальних закладах має ряд проблем. Основною з них є відсутність у студентів мотивації при вивченні математичних дисциплін. Здобувачі вищої освіти зазвичай не розуміють, як застосовувати отримані знання в професійній діяльності, що є кінцевою метою вивчення математики у вищому навчальному закладі. Пошук ефективних методів викладання математики - одна $з$ багатьох проблем вищої школи.

Аналіз останніх досліджень і публікацій. Про необхідність модернізації системи вищої освіти зазначається у багатьох дослідженнях з педагогіки. Ця необхідність обумовлена, в першу чергу, всебічною інформатизацією суспільства, потребою людей в використанні сучасних інформаційних технологій в усіх сферах їх життя, у тому числі, у навчанні. Про необхідність використання сучасних інформаційних технологій при викладанні математичних дисциплін у вищих навчальних закладах зазначено в роботі C.O. Семерікова. В роботі зроблено акцент на використанні мобільних інформаційних технологій, як засобу підвищення пізнавальної активності і самостійності студентів [3]. Ще однією причиною, яка обумовлює необхідність змін у системі вищої освіти, є потреба ринку праці у грамотних спеціалістах, здатних вирішувати різноманітні професійні проблеми. В роботі Т.В. Крилової зазначається, що вивчення математичних дисциплін у вищій школі повинно мати професійну спрямованість, бути менш формальним, наближеним до виробничої діяльності [4]. Про необхідність впровадження інноваційних технологій навчання, спрямованості системи університетської освіти на європейські та світові освітні стандарти наголошується у роботах Л.І. Золотаревської, Г.С. Швець, Ю.В. Бистрової тощо [5-7]. Проблемою інноваційного навчання в Україні займаються не тільки вітчизняні, але й зарубіжні дослідники. Так, у роботі O.P Yuzuk проаналізована система вищої освіти в Україні та дано рекомендації щодо ії вдосконалення орієнтуючись на польський досвід [8].

Отже, для ефективного вивчення вищої математики у ВНЗ потрібна нова, прогресивна методика подання навчального матеріалу, орієнтована на сучасні потреби суспільства. 3 метою підвищення мотивації студентів до навчання 
необхідно по-перше, проводити паралелі між компетенціями, які отримують здобувачі вищої освіти в процесі навчання та застосуванням цих компетенцій у професійній діяльності. Тобто треба робити акцент на практичному застосуванні отриманих теоретичних знань у майбутній професійній діяльності. По-друге, необхідно залучати до навчального процесу сучасні інформаційні технології (у тому числі мобільні інформаційні технології), застосування яких можна розглядати як альтернативу аналітичному розв'язку багатьох математичних задач [9]. Саме поєднання теорії, практики та інформаційних технологій у навчальному процесі дозволить зробити викладання математики більш зрозумілим та цікавим для студентів.

Мета статті - розроблення нової методики викладення курсу «Вища математика» у вищих навчальних закладах, яка матиме прикладну спрямованість і відповідатиме сучасним потребам суспільства.

Виклад основного матеріалу. В рамках проведеного дослідження, на основі результатів анкетування 70 студентів 1 курсу спеціальностей 051 «Економіка підприємства» та 073 «Менеджмент», було встановлено, що $80 \%$ опитуваних не мають інтересу до вивчення вищої математики. На питання: «Що, на вашу думку, може змінити ваше ставлення до вивчення дисципліни?», $68 \%$ студентів відповіли, що необхідно робити акцент на прикладному застосуванні отриманих знань. Тоді навчання буде більш цікавим і зрозумілим. Ще $12 \%$ зазначили, що не уявляють навчання без використання сучасних інформаційних технологій. Результати анкетування приведені на рисунку 1.

Наявність інтересу до навчання

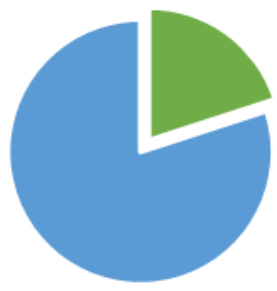

- $€$ інтерес донавчання (20\%)

- Немає інтересу до навчання (80\%)
Чого не вистачає у викладанні дисципліни?

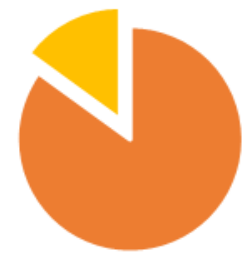

- Прикладне застосування отриманих знань $(68 \%)$

- Використання інформаційних технологій $(12 \%)$

Рис. 1 Результати анкетування серед студентів 1 курсу економічних спеціальностей

Отримані результати опитування збігаються 3 даними педагогічного спостереження, яке проводилося під час навчальних занять 3 вищої математики. Підводячи підсумок проведеним емпіричним дослідженням, можна зробити висновок, що треба коригувати існуючу методику викладання вищої математики у вищих навчальних закладах, приймаючи до уваги інтереси та потреби сучасної молоді.

На нашу думку, при викладанні навчального матеріалу треба додержуватися наступної схеми: 
Журнал«Герспективита інноваціїнукиљ

(Серія «Гедагогіка», Серія«Гцихологія», Серія«Медицина»

№(6) 2022

1. Загальна постановка задачі, ії зв'язок з майбутньою спеціальністю.

2. Формалізація задачі.

3. Аналітичний розв'язок посталеної задачі.

4. Чисельний розв'язок посталеної задачі із застосуванням сучасних інформаційних технологій.

5. Аналіз отриманих результатів, висновки, дискуси.

Одноосібно викладач виконує лише перші два пункти цієї схеми, останні три виконуються спільно зі студентами. При розв'язанні задач студенти поділяються на групи, кожна $з$ яких виконує окреме завдання. Такий спосіб викладання дозволяє підтримувати неперервний контакт зі студентською аудиторією, вчить працювати в команді, а застосування сучасних інформаційних технологій допомагає активізувати освітній процес.

Розглянемо, як можна викладати методи лінійної алгебри студентам економічних спеціальностей на прикладі розв'язання задачі міжгалузевого балансу. Отже, поставимо задачу. Припустимо, що весь виробничий комплекс поділено на $\mathrm{n}$ галезей, кожна з яких виробляє лише певний продукт, причому різні галузі виробляють різні продукти [10]. Потрібно знайти такий обсяг виробництва кожної з галузей, щоб задовольнити всі потреби у продукції цієї галузі. При цьому кожна галузь виступає з одного боку, як виробник даної продукції, а з іншого боку - як споживач і своєї, і виробленої іншими галузями продукції. Поставлена задача міжгалузевого балансу $\epsilon$ задачею макроекономіки, вона ставиться тоді, коли треба вирішити питання ефективного ведення багатогалузевого господарства. Математична модель цієї задачі була запропонована американським економістом В. Леонтьєвим [11].

Формалізуємо поставлену задачу. Математична модель міжгалузевого балансу має вигляд системи $n$ лінійних алгебраїчних рівнянь $3 n$ невідомими

$$
\left\{\begin{array}{c}
X_{1}=x_{11}+x_{12}+\cdots+x_{1 n}+Y_{1} \\
X_{2}=x_{21}+x_{22}+\cdots+x_{2 n}+Y_{2} \\
\cdots \cdots \cdots \cdots \cdots \cdots \cdots \cdots \cdots \cdots \cdots \cdots \cdots \\
X_{n}=x_{n 1}+x_{n 2}+\cdots+x_{n n}+Y_{n}
\end{array}\right.
$$

Модель (1) може бути записана у вигляді (2)

$$
X_{i}=\sum_{j=1}^{n} x_{i j}+Y_{i} \quad(i=1,2, \ldots n),
$$

де $X_{i}-$ загальний обсяг продукції i-ої галузі; $x_{i j}$-обсяг i-ої галузі, що потребує ј-та галузь в процесі виробництва; $Y_{i}$ - обсяг кінцевого продукту і-ої галузі для невиробничого споживання.

Розглянемо модель міжгалузевого балансу у вартісній формі. Введемо у розгляд коефіцієнти прямих матеріальних витрат. При цьому використаємо формулу

$$
a_{i j}=\frac{x_{i j}}{x_{i}}
$$


де $a_{i \bar{j}}-$ коефіцієнт прямих витрат продукції і-ої галузі на одиницю загального випуску і-ої галузі.

Коефіцієнти $a_{i \bar{j}}$ Утворюють матрицю коефіцієнтів прямих витрат

$$
A=\left(\begin{array}{ccc}
a_{11} & \cdots & a_{12} \\
\vdots & \ddots & \vdots \\
a_{n 1} & \cdots & a_{n n}
\end{array}\right)
$$

Приймаючи до уваги співвідношення (2)-(3) отримаємо систему (4)

$$
X_{i}=\sum_{j=1}^{n} a_{i j} x_{i j}+Y_{i} \quad(i=1,2, \ldots n)
$$

У матричній формі ця система прийме вигляд (5)

$$
\begin{aligned}
& \left(\begin{array}{ccc}
a_{11} & \cdots & a_{12} \\
\vdots & \ddots & \vdots \\
a_{n 1} & \cdots & a_{n n}
\end{array}\right)\left(\begin{array}{c}
X_{1} \\
\cdots \\
X_{n}
\end{array}\right)+\left(\begin{array}{c}
Y_{1} \\
\ldots \\
Y_{n}
\end{array}\right)=\left(\begin{array}{c}
X_{1} \\
\ldots \\
X_{n}
\end{array}\right) \\
& \text { або } \\
& X=A X+Y
\end{aligned}
$$

Із співвідношення (6) можна знайти матрицю кінцевої продукції $\mathrm{Y}$ при відомій матриці загального (валового) випуску $\mathrm{X}$, i навпаки, при заданій матриці кінцевої продукції Ү знайти матрицю валового випуску Х.

Розглянемо чисельну реалізацію моделі (6) на прикладі двох простих задач.

Задача 1. Відомі матриця валового випуску продукції галузі (матриця Х) і матриця коефіцієнтів прямих витрат (матриця А):

$$
X=\left(\begin{array}{l}
100 \\
250 \\
350
\end{array}\right), \quad A=\left(\begin{array}{lll}
0,2 & 0,1 & 0,1 \\
0,1 & 0,5 & 0,2 \\
0,1 & 0,1 & 0,4
\end{array}\right)
$$

Знайти матрицю обсягів кінцевої продукції Ү.

Розв'язання. Перепишемо рівність (6) у вигляді (7)

$Y=X-A X$

або

$Y=(E-A) X$,

де $E$-одинична матриця.

Використовуючи формулу (8) та правило множення матриць, знайдемо аналітичний розв'язок поставленої задачі. Отже, матриця обсягів кінцевої продукції має вигляд

$$
Y=(E-A) X=\left(\begin{array}{ccc}
0,8 & -0,1 & -0,1 \\
-0,1 & 0,5 & -0,2 \\
-0,1 & -0,1 & 0,6
\end{array}\right) \cdot\left(\begin{array}{c}
100 \\
250 \\
350
\end{array}\right)=\left(\begin{array}{c}
20 \\
45 \\
175
\end{array}\right)
$$

Знайдемо матрицю Y за допомогою матричного калькулятора Matrix Calculator. Результати аналітичного та чисельного розв'язку задачі збігаються (див рис. 2).

Проаналізуємо результати. Отже, ми отримали аналітичний та чисельний розв'язок задачі міжгалузевого балансу. За витратами часу ці два види розв'язку приблизно рівні. Але ситуація суттєво зміниться зі збільшенням 
Журнал«Герспективита іноваціїнауки

(Серія «Гедагогіка», Серія «Геихологія», Серія «Медицив»

№1(6) 2022

розмірності задачі. У такому разі перевагу слід віддавати чисельному розв'язку задачі.

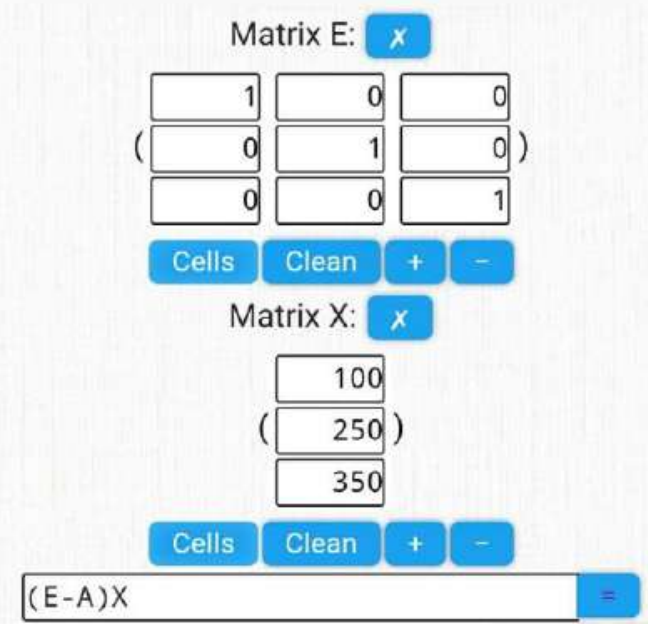

\section{MATRIX CALCULATOR}

Matrix A:

\begin{tabular}{|r|r|r|}
\hline 0,2 & 0,1 & 0,1 \\
\hline \hline 0,1 & 0,5 & 0,2 \\
\hline \hline 0,1 & 0,1 & 0,4 \\
\hline
\end{tabular}

\section{Insert in A}

Insert in B

\section{Clean}

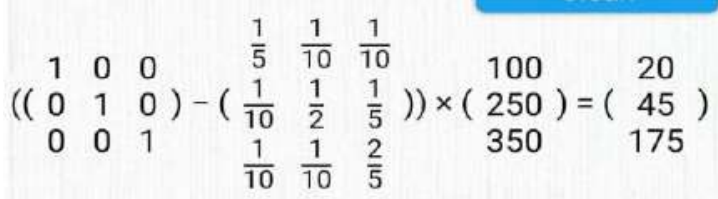

Puc. 2 Чисельний розв'язок задачі 1

Задача 2. Відомі матриця кінцевого обсягу продукції та матриця коефіцієнтів прямих витрат:

$$
Y=\left(\begin{array}{l}
300 \\
150 \\
400
\end{array}\right), \quad A=\left(\begin{array}{lll}
0,1 & 0,2 & 0,5 \\
0,5 & 0,1 & 0,2 \\
0,5 & 0,5 & 0,4
\end{array}\right)
$$

Знайти матрицю валового випуску продукції галузі.

Розв'язання. Приймаючи до уваги співвідношення (6) отримаємо наступну формулу

$$
X=(E-A)^{-1} \cdot Y
$$

\begin{tabular}{|c|c|c|c|c|c|c|c|c|c|c|c|c|c|c|}
\hline \multirow{2}{*}{\multicolumn{2}{|c|}{$\begin{array}{l}\text { Файл } \\
\text { T14 }\end{array}$}} & Главная & Вставка & \multicolumn{2}{|c|}{ Разметка страницы } & \multirow[t]{2}{*}{ Формулы } & \multirow{2}{*}{ Данные } & \multicolumn{2}{|c|}{ Рецензирование } & \multirow{2}{*}{ Вид } & \multirow[t]{2}{*}{ Справка } & \multicolumn{3}{|c|}{ Ч Что вы хотите сделать? } \\
\hline & & $\vdots$ & $x$ & $f_{x}$ & & & & & & & & & & \\
\hline \multicolumn{15}{|l|}{1} \\
\hline \multicolumn{15}{|l|}{2} \\
\hline 3 & \multicolumn{5}{|c|}{ Матриця коефіцієнтів прямих витрат } & \multicolumn{5}{|c|}{ Матриця обсягів кінцевого продукт } & \multicolumn{3}{|c|}{ Одинична матриця } & \\
\hline 5 & $A=$ & 0,1 & 0,5 & 0,2 & & $\mathbf{Y}$ & 250 & & & $E=$ & 0 & 1 & 0 & \\
\hline 6 & & 0 & 0,2 & 0,4 & & & 350 & & & & 0 & 0 & 1 & \\
\hline \multicolumn{15}{|l|}{7} \\
\hline \multicolumn{15}{|l|}{8} \\
\hline 9 & \multicolumn{3}{|c|}{ Матриця E-A } & & & \multicolumn{4}{|c|}{ Обернена матриця } & & & & & \\
\hline 10 & & 0,5 & $-0,1$ & 0 & & & & 2,10 & 0,48 & 0,16 & & & & \\
\hline 15 & & & & & \multicolumn{6}{|c|}{ Шукана матриця валового випуску продукції галузі } & & & & \\
\hline 16 & & & & & & & & & & & & & & \\
\hline 17 & & & & & & & 387,10 & & & & & & & \\
\hline 18 & & & & & & $x=$ & 935,48 & & & & & & & \\
\hline 19 & & & & & & & 895,16 & & & & & & & \\
\hline 20 & & & & & & & & & & & & & & \\
\hline
\end{tabular}

За даною формулою знайдемо матрицю X. Розрахунки будемо проводити у середовищі мобільного додатку MS Excel (див. рис. 3).

Pис. 3 Чисельний розв'язок задачі 2 
Проаналізуємо результати. Отже, ми отримали чисельний розв'язок задачі міжгалузевого балансу. У цьому випадку чисельний розв'язок $\epsilon$ менш трудомістким, ніж аналітичний розв'язок, тому ми вважатиме, що він $\epsilon$ більш доцільним при розв'язанні такого типу задач.

Робимо висновки по темі. В рамках цієї роботи ми навчилися виконувати дії над матрицями, познайомилися з мобільними додатками Matrix Calculator та MS Excel, використали їх можливості для отримання чисельного роз'язку задачі міжгалузевого балансу. Ставимо питання, яке спонукає студентів до дискусу: «Яка постановка задачі міжгалузевого балансу є більш доцільною: скільки сировини необхідно для випуску певного виду продукції, чи навпаки, скільки продукції певного виду можна виробити 3 наявної кількості сировини?»

Аналогічно тому, як було показано вище, можна викладати будь-який розділ курсу вищої математики. Достатньо лише знайти місце математики в конкретно взятій предметній області. А застосування інформаційних технологій зробить процес навчання більш цікавим та пізнавальним.

Висновки. Таким чином, форма подачі матеріалу в значній мірі впливає на якість сприйняття його студентами. Для ефективного вивчення вищої математики у вищих навчальних закладах освіти необхідно коректувати існуючі методики викладання, приймаючи до уваги інтереси та потреби студентської аудиторії. Запропонована в статті методика містить елементи інноваційної освіти та орієнтована на розвиток особистісного потенціалу слухачів. Навчаючись за цією методикою, студенти набувають навички роботи в команді, вчаться розв'язувати прикладні задачі професійної спрямованості, застосовуючи для цього новітні інформаційні технології.

\section{Лimepamypa:}

1. Гусак Л.П. Розвиток мотивів вивчення вищої математики на економічних спеціальностях ВНЗ. Науковий вісник Ужгородського наиіонального університету. Серія Педагогіка, соиіальна робота. 2015. Вип. 35. С. 56-59.

2. Готинчан I.3., Дрінь I.I. Про роль математики в системі професійної освіти майбутніх економістів. Проблеми освіти та методика викладання у вищій школі. 2019. Вип. 2 (74). С. 218-225.

3. Семеріков С.О., Словак К.І. Теорія і методика застосування мобільних математичних середовищ в процесі навчання вищої математики студентів економічних спеціальностей. Інформащійні технології $i$ засоби навчання. 2011. №1(21) URL: http://www.journal.iitta.gov.ua

4. Крилова Т.В., Гулєша О.М., Орлова О.Ю. Дидактичні засади фундаменталізації математичної освіти студентів нематематичних спеціальностей університетів. Дидактика математики: проблеми і дослідження: міжнар. збірник наукових робіт. Донецьк: ДонНУ, 2011. Вип. 35. С. 27-35.

5. Золотаревська Л. І. Інноваційна перебудова вищої освіти та модернізація системи підготовки фахівців. Тези науково-методичної конференції кафедр університету «Підготовка фахівиів нової генерації - завдання вищої освіти» (29 - 30 листопада 2017 року). Харків: Український державний університет залізничного транспорту, 2017. С. 18-19. 
6. Швець Г.О. Сучасні інноваційні методи викладання у вищій школі. Наукова думка сучасності і майбутнього: збірник наукових статей учасників IV Всеукраӥнськоӥ практично-пізнавальної конферениії (м. Дніпро, 9-26 вересня 2016 року). Дніпро: Видавництво НМ, 2016. С. 19-22.

7. Бистрова Ю.В. Інноваційні методи навчання у вищій школі України. Право та інновачійне суспільство. 2015. №1 (4). С. 27-33.

8. Yuzuk O.P, Vysochan L.M., Grytsyk N.V. Innovative teaching methods in higher education institutions of Poland and Ukraine. Zeszyty Naukowe Wyższej Szkoły Technicznej w Katowicach. 2019. № 11. pp. 45-50.

9. Насонова С.С., Рижков Е.В. Застосування офісних інформаційних технологій як альтернатива програмному розв'язанню економічних задач на графовій моделі. Адаптивне управління: теорія $і$ практика. №10(20), 2021. URL: https://amtp.org.ua/index.php/journal2/ article/view/365/316

10. Грисенко М.В. Математика для економістів: навчальний посібник. Київ: ВПЦ «Київський університет», 2005. 586 с.

11. Лугінін О.С. Економетрія: навчальний посібник. Київ: Центр учбової літератури, 2008. $278 \mathrm{c}$.

\section{References:}

1. Husak L.P. (2015). Rozvytok motyviv vyvchennia vyshchoi matematyky na ekonomichnykh spetsialnostiakh VNZ [Development of motives for studying higher mathematics in economic specialties of higher education] Naukovyi visnyk Uzhhorodskoho natsionalnoho universytetu. Seriia Pedahohika, sotsialna robota - Scientific Bulletin of Uzhhorod National University. Series Pedagogy, social work, issue 35, pp. 56-59. [in Ukrainian]

2. Hotynchan I.Z, Drin I.I. (2019). Pro rol matematyky v systemi profesiinoi osvity maibutnikh ekonomistiv [On the role of mathematics in the system of vocational education of future economists]. Problemy osvity ta metodyka vykladannia u vyshchii shkoli - Problems of education and methods of teaching in higher education, issue 2 (74), pp. 218-225. [in Ukrainian]

3. Semerikov S.O., Slovak K.I (2011) Teoriia i metodyka zastosuvannia mobilnykh matematychnykh seredovyshch $\mathrm{v}$ protsesi navchannia vyshchoi matematyky studentiv ekonomichnykh spetsialnostei [Theory and methods of application of mobile mathematical environments in the process of teaching higher mathematics to students of economic specialties]. Informatsiini tekhnolohii $i$ zasoby navchannia - Information technologies and teaching aids, №1 (21). Retrieved from: http://www.journal.iitta.gov.ua [in Ukrainian]

4. Krylova T.V. (2011). Dydaktychni zasady fundamentalizatsii matematychnoi osvity studentiv nematematychnykh spetsialnostei universytetiv [Didactic bases of fundamentalization of mathematical education of students of non-mathematical specialties of universities]. Dydaktyka matematyky: problemy $i$ doslidzhennia: mizhnarodnyi zbirnyk naukovykh robit - Didactics of mathematics: problems and research: international collection of scientific works. Donetsk: DonNU, issue 35, pp. 27-35. [in Ukrainian]

5. Zolotarevska L.I. (2017) Innovatsiina perebudova vyshchoi osvity ta modernizatsiia systemy pidhotovky fakhivtsiv [Innovative restructuring of higher education and modernization of the training system]. Pidhotovka fakhivtsiv novoi heneratsii - zavdannia vyshchoi osvity: tezy naukovo-metodychnoi konferentsii kafedr universytetu - Training of new generation specialists the task of higher education: abstracts of papers of the scientific-methodical conference of university departments. Kharkiv: Ukrainskyi derzhavnyi universytet zaliznychnoho transport, pp. 18-19. [in Ukrainian]

6. Shvets H.O. (2016) Suchasni innovatsiini metody vykladannia u vyshchii shkoli [Modern innovative methods of teaching in higher education]. Zbirnyk naukovykh statei uchasnykiv IV Vseukrainskoi praktychno-piznavalnoi konferentsii «Naukova dumka suchasnosti $i$ 
maibutnoho» - Collection of scientific articles of the participants of the IV All-Ukrainian practical-cognitive conference "Scientific thought of the present and the future". Dnipro: NM Publ., pp. 19-22. [in Ukrainian]

7. Bystrova Yu.V. (2015). Innovatsiini metody navchannia u vyshchii shkoli Ukrainy [Innovative teaching methods in higher education in Ukraine]. Pravo ta innovatsiine suspilstvo Law and innovation society, №1 (4). pp. 27-33. [in Ukrainian]

8. Yuzuk O.P, Vysochan L.M., Grytsyk N.V. (2019) Innovative teaching methods in higher education institutions of Poland and Ukraine. Zeszyty Naukowe Wyższej Szkoły Technicznej w Katowicach, № 11.pp. 45-50. [in English]

9. Nasonova S.S., Ryzhkov E.V. (2021) Zastosuvannia ofisnykh informatsiinykh tekhnolohii yak alternatyva prohramnomu rozviazanniu ekonomichnykh zadach na hrafovii modeli [The use of office information technology as an alternative to software solutions to economic problems on the graph model]. Adaptyvne upravlinnia: teoriia i praktyka - Adaptive control: theory and practice. №10(20). Retrieved from:

https://amtp.org.ua/index.php/journal2/article/view/365/316 [in Ukrainian]

10. Hrysenko M.V. (2005) Matematyka dlia ekonomistiv: navchalnyi posibnyk [Mathematics for economists: a textbook]. Kyiv: Kyivskyi universytet Publ., 586 p. [in Ukrainian]

11. Luhinin O.Ie. (2008) Ekonometriia: navchalnyi posibnyk [Econometrics: Tutorial]. Kyiv: Tsentr uchbovoi literatury, 278 c. [in Ukrainian] 